\title{
Impact fatigue behaviour of carbon fibre-reinforced vinylester resin composites
}

\author{
RITA ROY, B K SARKAR*, A K RANA ${ }^{\dagger}$ and N R BOSE \\ Department of Materials Science, Indian Association for the Cultivation of Science, 2A \& B, Raja SC Mallick Road, \\ Calcutta 700 032, India \\ ${ }^{\dagger}$ Indian Jute Industries Research Association, Calcutta 700 088, India \\ Central Glass and Ceramic Research Institute, Calcutta 700 032, India
}

MS received 24 July 2000; revised 27 October 2000

\begin{abstract}
Two types of unidirectional carbon fibre, one of high strength (DHMS) and another of medium strength (VLMS) reinforced vinylester resin composites have been examined for their impact fatigue behaviour over $10^{4}$ impact cycles for the first time. The study was conducted using a pendulum type repeated impact apparatus specially designed and constructed for the purpose. A well-defined impact fatigue behaviour (S-N type curve) curve has been demonstrated. It showed a plateau region of 10-10 2 cycles immediately below the single cycle impact strength, followed by progressive endurance with decreasing impact loads, culminating in an endurance limit at about $71 \%$ and $85 \%$ of the single impact strength for DHMS-48 and VLMS-48, respectively. Analysis of the fractured surfaces revealed primary debonding, fibre breakage and pull-out at the tensile zone of the samples and a shear mode of fracture with breakage of fibre bundles at the compressive zone of the samples. The occurrence of a few major macrocracks in the matrix with fibre breakage at the high load-low endurance region and development of multiple microcracks in the matrix, coalescing and fibre breakage at the low-load-high endurance region have been inferred to explain the fatigue behaviour of the composites examined.
\end{abstract}

Keywords. Repeated impact; carbon fibre; vinylester resin; residual stress; modulus; toughness; impact energy.

\section{Introduction}

Fatigue is known to be responsible for the majority of failures of structural components (Dauskardt et al 1993) and carbon fibre reinforced polymer composites are no exception. The subject has assumed more importance in recent times because of its wide use as structural components in aerospace applications. The sports goods in particular, like tennis rackets, golf heads, boat hulls where the sustenance of repeated impacts during handling and use has drawn the attention of the designers. These structures often encounter fluctuating loads, causing degradation of the materials under fatigue.

Studies have been made on the cyclic fatigue under normal tension-tension, tension-compressive and bending of carbon fibre reinforced polymer composites. Notable amongst these are the works of Gamstedt and Talreja (1999) and Wyrick and Adams (1988). Gamstedt and Talreja (1999) related their observations on micromechanism failures to measure fatigue life behaviour under tension loading, and postulated a three-region fatigue life diagram having a horizontal portion at high strains, followed by a slope having progressive endurance at

\footnotetext{
*Author for correspondence
}

lower applied strains culminating into an endurance limit of no failure.

Literature on the behaviour of glass/carbon fibre reinforced composites under repeated impact loading has been rather scarce. Notable amongst those few studies made on impact fatigue behaviour of composites, are the experiments conducted by Jang et al (1991, 1992) on graphite, aramid and glass fibre reinforced epoxy composite laminates under single and repeated impacts. Their results indicated the existence of a critical incident energy $E_{\mathrm{c}}$, above which delaminations occurred in a given composite at the first impact. Their observations were limited to only $10^{3}$ cycles maximum and hence, no significant understanding under long endurance at sub critical stresses could be derived. A theoretical lifetime analysis was developed from the microscopy performed (Lhymn $1985 \mathrm{a}, \mathrm{b})$ on the impact fatigued specimens of a short E-glass fibre/polypropylene-sulfide composite. Agarwal and Joneja (1979) observed that stiffness of the unidirectional glass fibre reinforced epoxy specimens decreased progressively with increasing number of cycles. However, for more than half of their fatigue life specimens exhibited only a marginal change in stiffness. Only between 60$90 \%$ of fatigue life a significant drop in stiffness to about half the first cycle stiffness occurred. After the significant drop, stiffness gradually decreased to about $20 \%$ of its 
initial value. At this stage stiffness decreased very rapidly to complete failure within few cycles. The residual tensile and compressive strengths of selected carbon fibre reinforced epoxy resin composites subjected to only around $10^{2}$ impacts were found to degrade sharply (Wyrick and Adams 1988). The drop in strength properties increased with increasing impact loads. A lowenergy impact was exerted on a laminate and invisible damage occurred as a result of the contact stresses between the impactor and the laminate (Rotem 1988). The damage zone grew and caused a certain amount of strength and modulus reduction.

Since polymer matrices constitute a major constituent in a composite its behaviour under repeated loading conditions have been addressed by several investigators. There have been few reported studies on the impact fatigue response of polymers. The response of the ultrahigh molecular weight linear polyethylene under low cycle ( $<20$ cycles), repeated impacting of notched samples under three-point bending was studied by Bhateja et al (1979). Unnotched polycarbonate under a repeated dropped weight, three-point bending apparatus, an S/N type failure was reported by Ohishi et al (1976). The effect of repeated impact on polymer surfaces in terms of heat generation and mechanochemical reactions has been investigated (Schater et al 1979), while the surface damage due to low velocity, angled impacts on polymethylmethacrylate was examined by Studman and Field (1977). These investigations were basically concerned with wear resistance properties of the polymers. An impact fatigue test for studying the repeated biaxial impact load response of polymers was designed by Takemori (1982) who found that under impact fatigue, cracks initiated on the bottom surface of the plate-like polycarbonate samples where high biaxial tensile stresses exited. The development of impact fatigue cracks, the lifetime behaviour and the change in mechanical properties after partial impact fatigue were also discussed. Drawing analogy from the impact fatigue behaviour of brittle ceramics (Maity et al 1994; Maity and Sarkar 1995), where moisture related delayed fracture and microplasticity have been attributed, it is expected that the behaviour of glass/carbon fibre reinforced polymer composites under repeated impact fatigue could behave similarly.
Ambiguity still remains on the existence of a welldefined S-N type fatigue curve with an endurance limit under repeated impact loading for carbon fibre reinforced polymer composites. Explanations of the failure mechanisms have also remained incomplete particularly when the composites failed after long endurances beyond hundreds of subcritical impact stress cycles. Hence, an impact fatigue study has been designed to assess the behaviour of carbon fibre reinforced vinylester composite material under repeated impact loads and to demonstrate the existence of a fatigue curve with an endurance limit. From the fractographic analysis an understanding of the basic failure mechanism, during repeated impact fatigue has been attempted.

\section{Experimental}

\subsection{Material}

Two types of carbon fibres measured in INSTRON 5500R, one having Young's modulus of $292.2 \mathrm{GPa}$, tensile strength of $4.55 \mathrm{GPa}$ and failure strain of $0.02 \%$ and the other having Young's modulus of $244.9 \mathrm{GPa}$, tensile strength of $3.08 \mathrm{GPa}$ and $0.01 \%$ of failure strain obtained from DRDL and VSSC respectively were used as reinforcing material in vinylester resin composites. The values are depicted in table 1 . The resin used was a Bakellite Hylame product, grade HPR 8171, having a density of $1.21 \mathrm{~g} / \mathrm{cm}^{3}$, flexural strength of $120.7 \mathrm{MPa}$ and modulus of 2.5-3 GPa. MEKP, cobalt napthalene and $\mathrm{N}-\mathrm{N}$ dimethyl aniline were used as catalyst, accelerator and promoter, respectively.

\subsection{Sample preparation}

Carbon fibre reinforced vinylester resin composites were fabricated in the form of cylindrical rods of $\sim 180 \mathrm{~mm}$ length and $4 \mathrm{~mm}$ of internal diameter. Hollow cylindrical glass tubes (internal diameter of $4 \mathrm{~mm}$ ) were taken to act as mould. The resin was mixed with accelerator, promoter and catalyst (1\% each). The carbon fibres were soaked in the mixed resin and the wetted fibres were pulled by hand through the glass tube. To maintain a particular wt $\%$ of carbon fibre in the composite, same weight of carbon

Table 1. Mechanical properties of DHMS and VLMS fibres under tension.

\begin{tabular}{|c|c|c|c|c|c|c|c|c|}
\hline \multirow{2}{*}{$\begin{array}{l}\text { Type of } \\
\text { fibre }\end{array}$} & \multicolumn{2}{|c|}{$\begin{array}{l}\text { Load } \\
(\mathrm{N})\end{array}$} & \multicolumn{2}{|c|}{$\begin{array}{l}\text { Stress at max. load } \\
\qquad(\mathrm{GPa})\end{array}$} & \multicolumn{2}{|c|}{ Strain at max. load } & \multicolumn{2}{|c|}{$\begin{array}{l}\text { Modulus } \\
\quad(\mathrm{GPa})\end{array}$} \\
\hline & Mean & S.D. & Mean & S.D. & Mean & S.D. & Mean & S.D. \\
\hline DHMS & $0 \cdot 1303$ & 0.0339 & $4 \cdot 55$ & $1 \cdot 2$ & 0.0168 & 0.0034 & $292 \cdot 2$ & $32 \cdot 6$ \\
\hline VLMS & 0.0991 & 0.0234 & 3.08 & $7 \cdot 3$ & $0 \cdot 0139$ & 0.0031 & 244.9 & $29 \cdot 5$ \\
\hline
\end{tabular}

S.D.: Standard deviation. 
fibres as that of each glass tube length were taken. The pultruded samples within the glass tube were cured at room temperature for $24 \mathrm{~h}$ followed by post curing in an oven at $80^{\circ} \mathrm{C}$ for $4 \mathrm{~h}$. The glass tubes were broken clean to release the composite rods.

The two ends of the composite rods remaining outside the glass tube were then cut off and the length, $L$ and weight, $W$ of the composite rods were measured. The weight, $W_{1}$ of length, $L$ of carbon fibres was measured initially. The wt\% carbon fibre was thus calculated using the formula

$$
\text { Carbon fibre content }(\mathrm{wt} \%)=\left(W_{1} / W\right) \times 100 \text {. }
$$

By the above calculation, $48 \%$ carbon fibre loading was achieved for both types of composites prepared. The composites prepared with superior and weaker carbon fibres with respect to their sources were designated as DHMS-48 and VLMS-48 respectively.

\section{$2 \cdot 3$ Repeated impact apparatus}

A special swinging pendulum type impact fatigue tester (Sarkar and Glinn 1971; Maity and Sarkar 1995) based on the principles of Charpy Impact Tester was designed and fabricated in the laboratory (figure 1). It consists of a horizontal shaft to which was attached a rotating circular disc. The circular disc was rotated by a pulley and motor system. A pendulum hammer arm, with a cylindrical hammer $(h)$, was attached to the other end of the horizon-

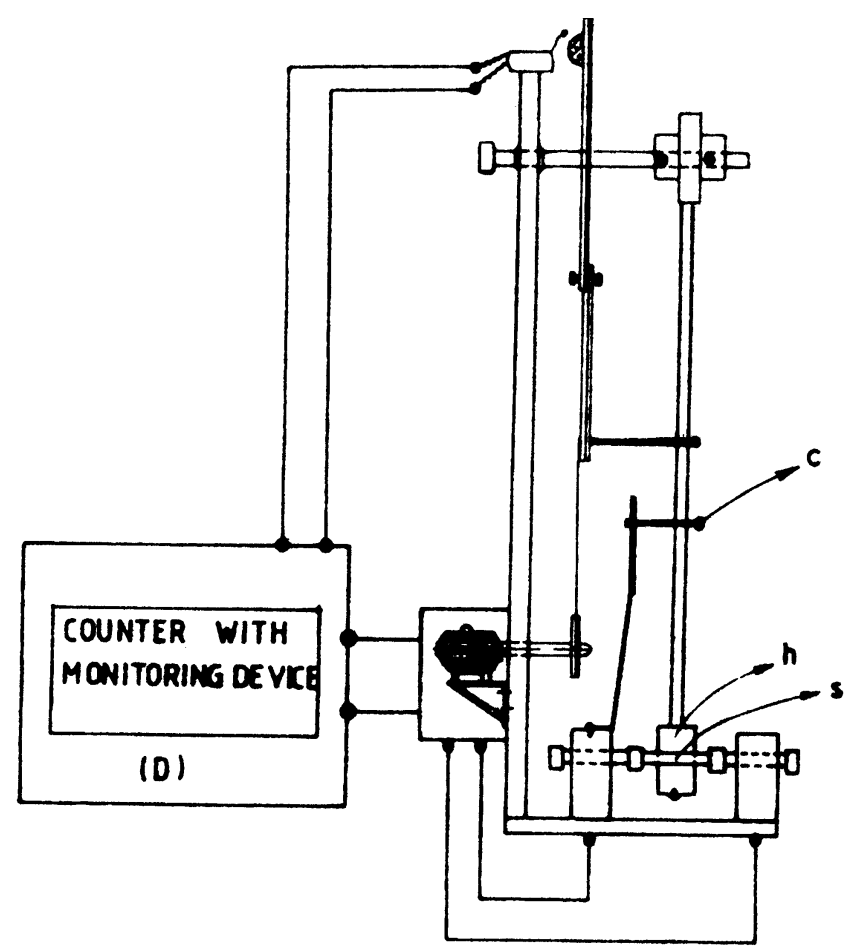

Figure 1. Schematic diagram of repeated impact fatigue apparatus. tal shaft. A trigger mechanism was fixed on one side of the circular disc that passed through the sensor once during each revolution, thus registering the number of impacts. A spring-loaded pick up arm, attached to the circular disc, carried the pendulum hammer up to a predetermined impact angle setting device $(c)$ height during each revolution. Upon contacting the preset trigger the pick up arm retracts allowing the pendulum arm to drop onto the specimen $(s)$ held horizontally between two tapered conical cups, screw mounted on the platforms. After each impact the free hanging hammer was picked up to the impact angle setting device again and then released till the specimen fractured, and the number of impacts to fracture was recorded by means of a 6-digit electromagnetic (resettle) counter. The specimen grips were wired into an electrical circuit with a monitoring device $(D)$, which, when broken, stopped the machine. Impact frequency was set at 6 impacts/min demonstrated schematically in figure 2 .

\section{$2 \cdot 4$ Single blow impact tests}

Energy loss was calculated by the following steps:

Impact energy $(E)$ upon the specimen was calculated according to the formula

$$
E=m g h(1-\cos \theta),
$$

where $m$ is the mass of the hammer, $g$ the acceleration due to gravity, $h$ the height of the pendulum arm and $\theta$ the angle of release.

The experiments were conducted, using a hammer of weight $0.235 \mathrm{~kg}$, and pendulum arm of $30.5 \mathrm{~cm}$. The hammer was released from various angles in the range from $80^{\circ}$ to $25^{\circ}$, and the final angle of swing was noted. The differences between the two swings with and without a broken specimen, converted to the energy $(\mathrm{N}-\mathrm{mm})$, on

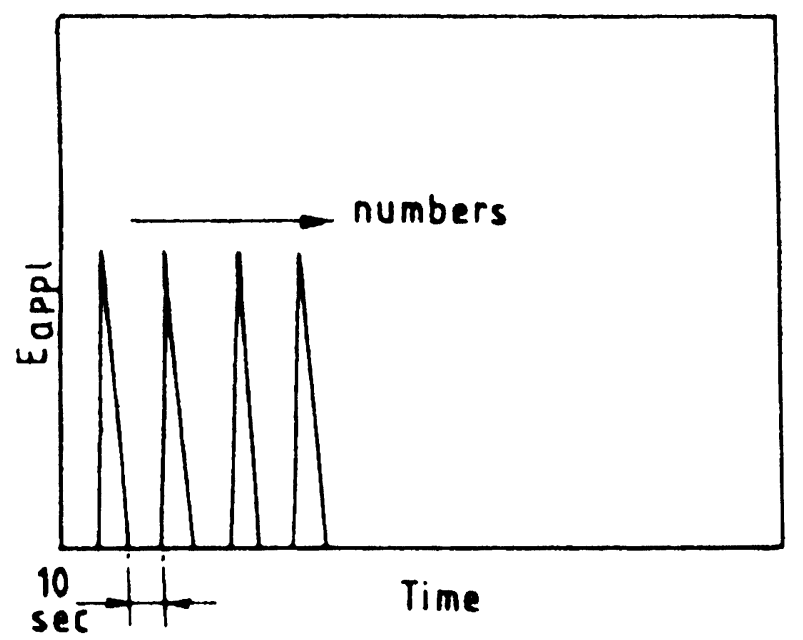

Figure 2. Schematic representation of the frequency of applied impact energy $\left(E_{\text {appl }}\right)$ with time $(t)$. 
account of the losses incurred due to windage, friction and toss were determined (Maity and Sarkar 1995).

\subsection{Repeated impact tests}

The single impact fracture energy (critical) value was obtained by reducing the angle of swing starting from a high angle to a value where the sample sustained the impact without fracture. Five samples were tested at each impact. The critical angles at which the DHMS-48 and VLMS-48 samples broke in a single blow were $80^{\circ}$ and $65^{\circ}$ respectively. The angles were then reduced progressively by a few degrees at a time and the number of impacts sustained at each angle (impact energy) were noted to determine the fatigue ( $\mathrm{S}-\mathrm{N}$ type) curve. The tests were terminated at around $10^{4}$ impact cycles at an impact energy level of $160 \cdot 5 \mathrm{~N}-\mathrm{mm}$ for DHMS-48 and $60 \cdot 1 \mathrm{~N}-\mathrm{mm}$ for VLMS-48 composite samples where the samples withstood without fracture. At these values the samples were considered to have an endurance limit. Unbroken samples were also tested for their residual mechanical properties at about $50 \%$ of the endured number of cycles $(50 \%-\mathrm{N})$ at each subcritical impact loads.

The mechanical properties like flexural strength, modulus and toughness of DHMS-48 and VLMS-48 composites for both the original and $50 \%-\mathrm{N}$ samples were determined by the three-point bend test in an INSTRON 4303 machine in accordance with ASTM D790 M-81.

Flexural strength and flexural modulus were measured using the following equation respectively.

$$
\text { Flexural strength }=8 P L / \pi d^{3},
$$

and

$$
\text { Flexural modulus }=4 m L^{3} / 3 \pi d^{4},
$$

where $P$ is the load, $L$ the span, $d$ the diameter of specimen and $m$ the slope of the initial straight line portion of the load-displacement curve.

Microstructures of the fractured surfaces of both the samples under three-point bend tests as well as under repeated impact tests were examined to ascertain the mode of failure.

\section{Results and discussion}

The load displacement curves for (a) DHMS carbon fibre and (b) VLMS carbon fibre are shown in figure 3. The DHMS fibres broke at a maximum load of $0.1303 \mathrm{~N}$ whereas the VLMS fibres broke at $0.0991 \mathrm{~N}$ load.

The flexural properties for DHMS-48 and VLMS-48 composite samples are presented in table 2. The flexural strength, modulus and toughness values for the two sets of composites were $675.44 \mathrm{MPa}, 37.94 \mathrm{GPa}, 25.71 \mathrm{KJ} / \mathrm{M}^{2}$ and $422.9 \mathrm{MPa}, 13.39 \mathrm{GPa}$ and $22.54 \mathrm{KJ} / \mathrm{M}^{2}$ respectively. VLMS-48 composites with weaker carbon fibres resulted in lower composite properties.

Typical load-displacement curves for (a) DHMS-48 composite and (b) VLMS-48 composite are compared in figure 4. Examinations of load-displacement curves showed a substantially different picture between the two sets of composites. The displacements at the breaking loads were about $2 \mathrm{~mm}$ for DHMS-48 and $3.2 \mathrm{~mm}$ for VLMS-48 composites before final fracture. The curve for

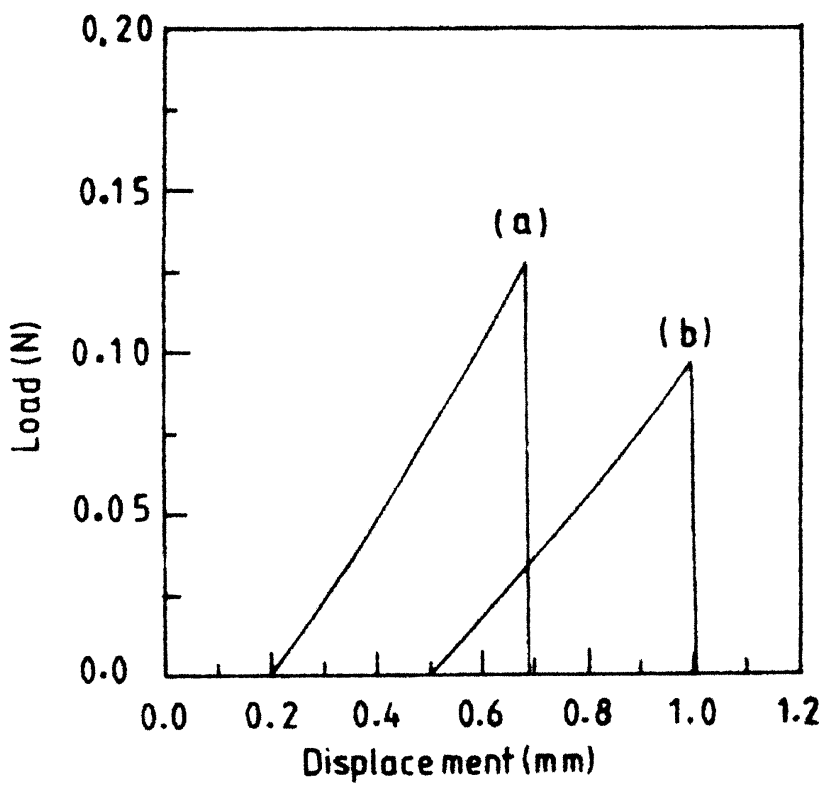

Figure 3. Load-displacement curves: (a) DHMS fibre and (b) VLMS fibre.

\begin{tabular}{|c|c|c|c|c|c|c|c|c|}
\hline \multirow{2}{*}{$\begin{array}{l}\text { Type of } \\
\text { composite }\end{array}$} & \multicolumn{2}{|c|}{$\begin{array}{l}\text { Flexural strength } \\
(\mathrm{MPa})\end{array}$} & \multicolumn{2}{|c|}{$\begin{array}{l}\text { Modulus } \\
\text { (GPa) }\end{array}$} & \multicolumn{2}{|c|}{$\begin{array}{l}\text { Energy to break } \\
\text { (J) }\end{array}$} & \multicolumn{2}{|c|}{$\begin{array}{l}\text { Toughness } \\
\left(\mathrm{KJ} / \mathrm{M}^{2}\right)\end{array}$} \\
\hline & Mean & S.D. & Mean & S.D. & Mean & S.D. & Mean & S.D. \\
\hline & & & & & & & & \\
\hline VLMS-48 & $422 \cdot 9$ & $4 \cdot 04$ & $13 \cdot 39$ & $1 \cdot 39$ & 0.2831 & $0 \cdot 017$ & 22.54 & $1 \cdot 36$ \\
\hline
\end{tabular}

Table 2. Mechanical properties of DHMS-48 and VLMS-48 composites.

S.D.: Standard deviation. 
DHMS-48 exhibits a linear elastic increase up to the maximum load of $0.33 \mathrm{KN}$, followed by a small drop in strength of $617.8 \mathrm{MPa}$. This is indicative of the onset of matrix cracking, debonding and a few fibres fracture. The load then dropped sharply with fibre fracture and pull-out. In contrast, the load for the VLMS-48 composites dropped off sharply after the peak load at $0.23 \mathrm{KN}$ to a total fracture. The work of fracture or the rupture energy at the peak load for the two sets were $25 \cdot 71 \mathrm{KJ} / \mathrm{M}^{2}$ and $22.54 \mathrm{KJ} / \mathrm{M}^{2}$ respectively.

The critical impact strength for DHMS-48 was $562.6 \mathrm{~N}-\mathrm{mm}$ against $394.6 \mathrm{~N}-\mathrm{mm}$ of VLMS-48. On reducing the applied impact energy the composite samples sustained progressively larger numbers of impacts. The fatigue results obtained for both the carbon fibre reinforced composites are depicted in figure 5. A typical S-N type curve is evident having progressive endurance with decreasing applied impact loads. In conformity with Gamstedt and Talreja (1999) the curves essentially displayed three regions having a plateau (region I) at the higher impact loads followed by progressive increase in endurances with decreased impact loads (region II) to an endurance limit (region III) at $160 \cdot 5 \mathrm{~N}-\mathrm{mm}$ for DHMS-48 composite and $60 \cdot 1 \mathrm{~N}-\mathrm{mm}$ for VLMS-48 composites after impact fatigued to about $10^{4}$ cycles. The ratio $E_{\mathrm{I}} / E_{\mathrm{c}}$ for DHMS-48 was 0.29 while for VLMS-48 it was $0 \cdot 15$, where $E_{\mathrm{I}}$ is taken as the applied impact energy at endurance limit and $E_{\mathrm{c}}$ the single impact (critical) energy value. The difference in fatigue behaviour between the two varieties of composites is better demonstrated when the ratio of the applied subcritical impact energy $\left(E_{\mathrm{I}}\right)$ to

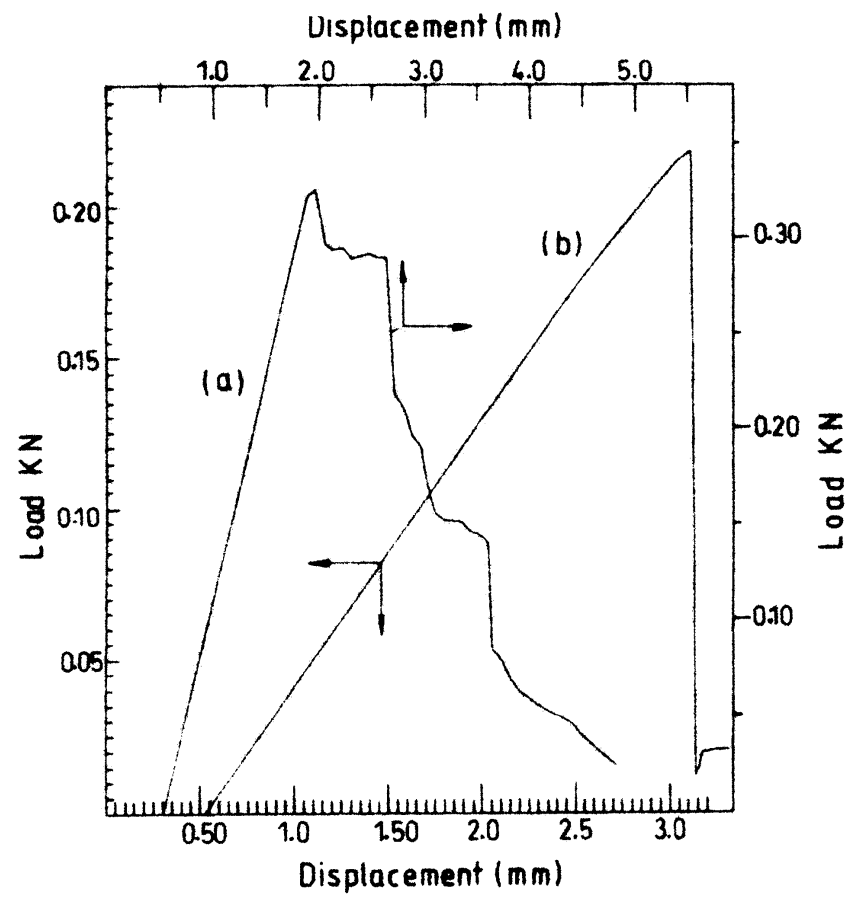

Figure 4. Load-displacement curves: (a) DHMS-48 composite and (b) VLMS-48 composite. critical impact energy $\left(E_{\mathrm{c}}\right)$ against number of cycles is plotted and is shown in figure 6 . The fatigue behaviour of the DHMS-48 composite was thus found to be superior to that of VLMS-48 composite owing to the superior fibre properties in the former. A clear deflection at around $10^{2}$ impact cycles from a shallow to a sharp drop was evident. The shallow drop in fatigue behaviour in region I is similar to the study made by Gamstedt and Talreja (1999).

The unbroken impact fatigued samples at about $50 \%$ of the endured number of cycles $(50 \%-\mathrm{N})$ at each subcritical impact loads were measured for their residual strength, modulus and toughness properties in an INSTRON 4303 machine in accordance with ASTM D790M-81. The results are shown in figures $7-9$. At $160 \cdot 5 \mathrm{~N}-\mathrm{mm}$ impact energy level where the DHMS-48 specimens endured about 8431 impact cycles (region III) without breakage, there had been a decrease of the residual strength by about $27 \%$, modulus by $11 \%$ and toughness by $27 \%$. At the lowest impact energy level of $60 \cdot 1 \mathrm{~N}-\mathrm{mm}$, the VLMS-48 specimens endured about 3256 impact cycles (region III) without

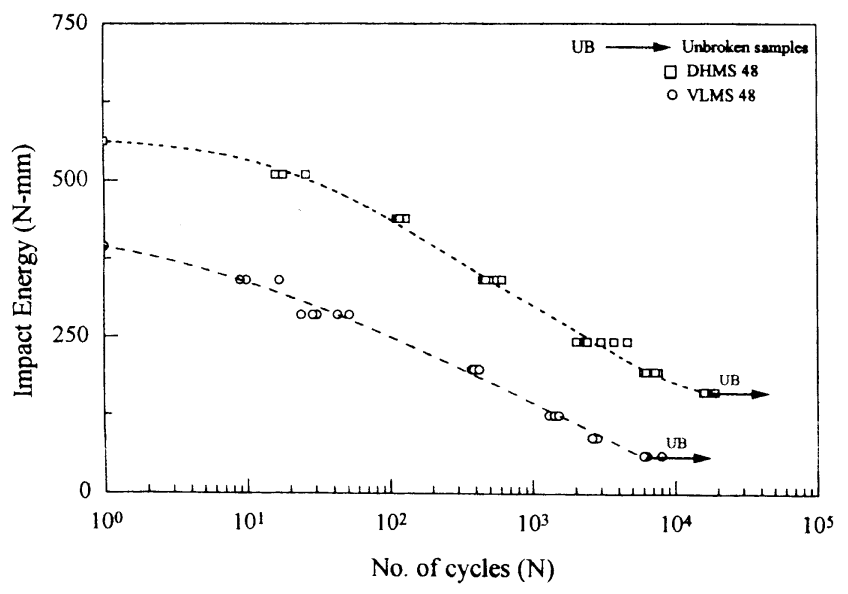

Figure 5. Impact energy vs no. of cycles $(N)$ curves for DHMS-48 and VLMS-48 composites.

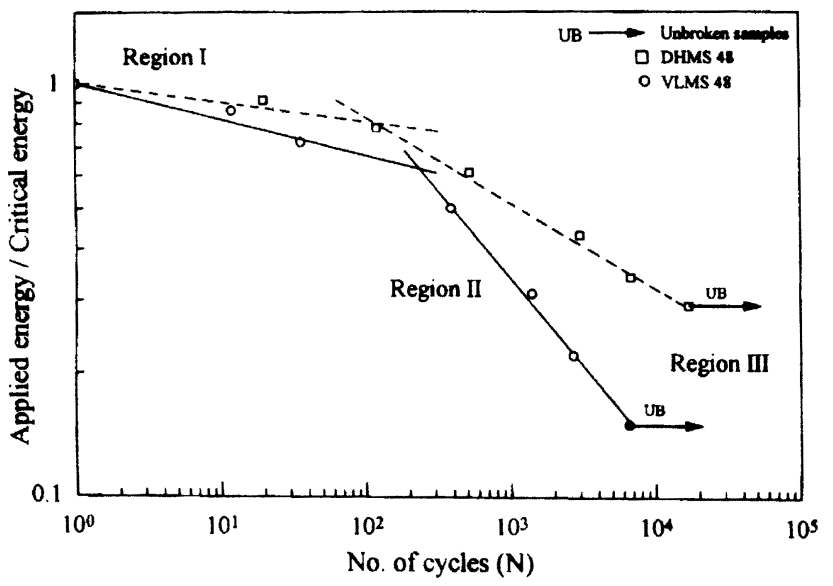

Figure 6. Ratio between applied impact energy and critical impact energy for DHMS-48 and VLMS-48 composites. 


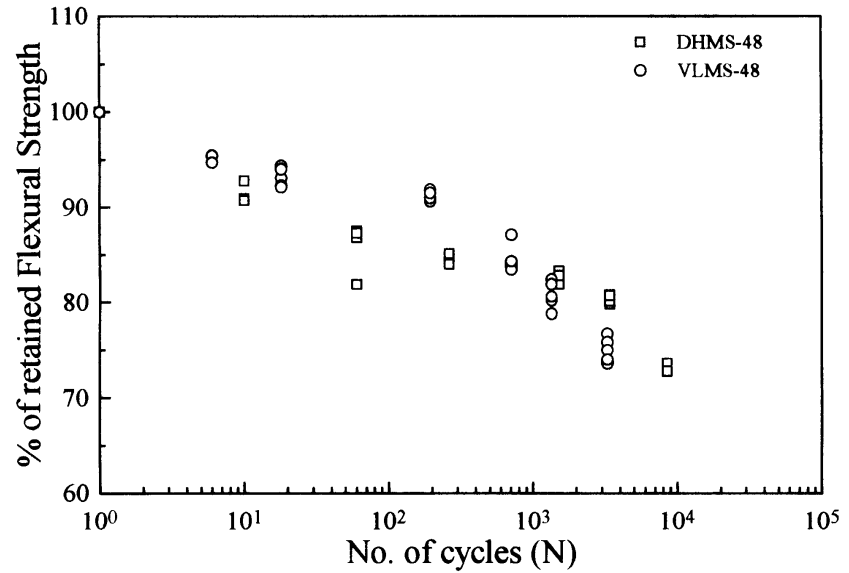

Figure 7. Residual flexural strength (\%) after $50 \%-\mathrm{N}$ for DHMS-48 and VLMS-48 composites.

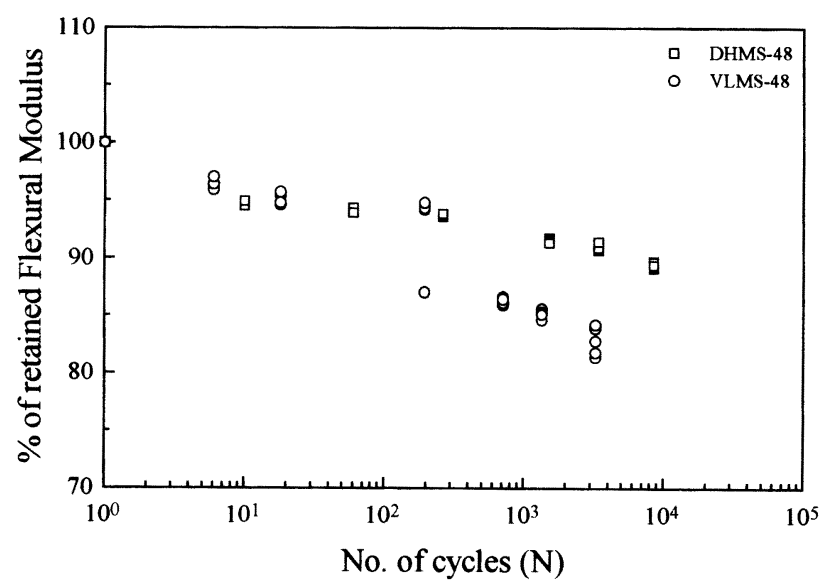

Figure 8. Residual modulus (\%) after $50 \%-\mathrm{N}$ for DHMS-48 and VLMS-48 composites.

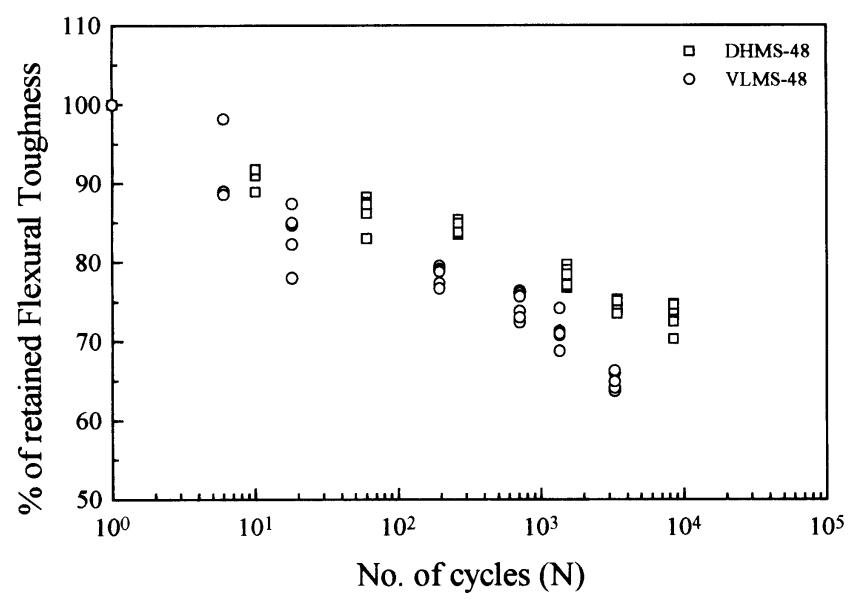

Figure 9. Residual toughness (\%) after 50\%-N for DHMS-48 and VLMS-48 composites. breakage and there had been a decrease in the residual strength by $25 \%$, modulus by $18 \%$ and toughness by $35 \%$. Although there had been a drop in properties, yet the composites sustained the fatigue loading without failure. The drops in the \% residual strength properties for both the composites were virtually the same but a difference was observed for \% modulus and \% toughness properties, the VLMS-48 composites having lower retained properties than the other. This could be attributed to the predominantly direct fracture of the fibres preceded by debonding and matrix cracking without much intermediary failure steps. Unlike Wyrick and Adams (1988) the drop in the properties were relatively less till large number of impacts were endured.

The fractured surfaces of the samples were examined under SEM. Uniform distribution of the fibres within the

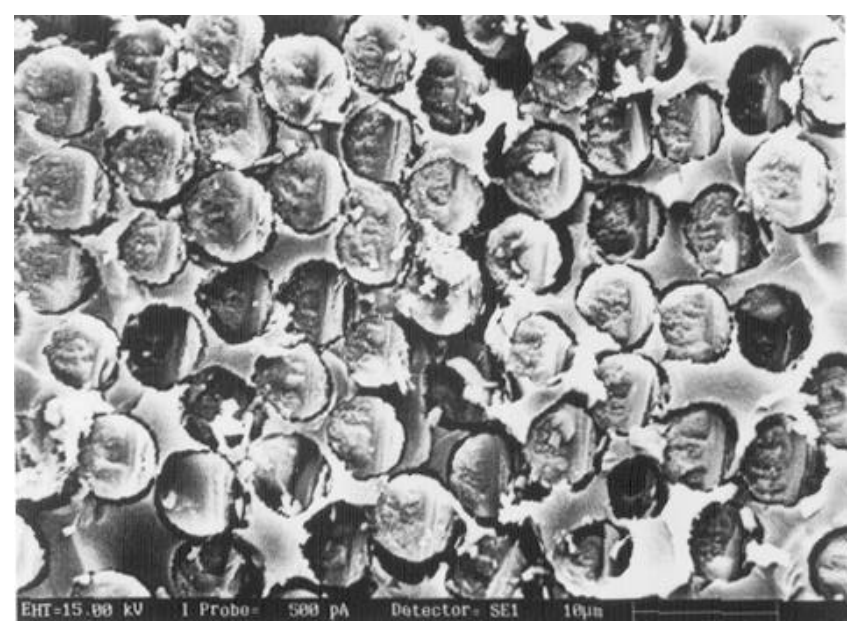

Figure 10. SEM photograph of DHMS-48 composite showing interface debonding and a shear type of fracture under single impact energy of $562.0 \mathrm{~N}-\mathrm{mm}$.

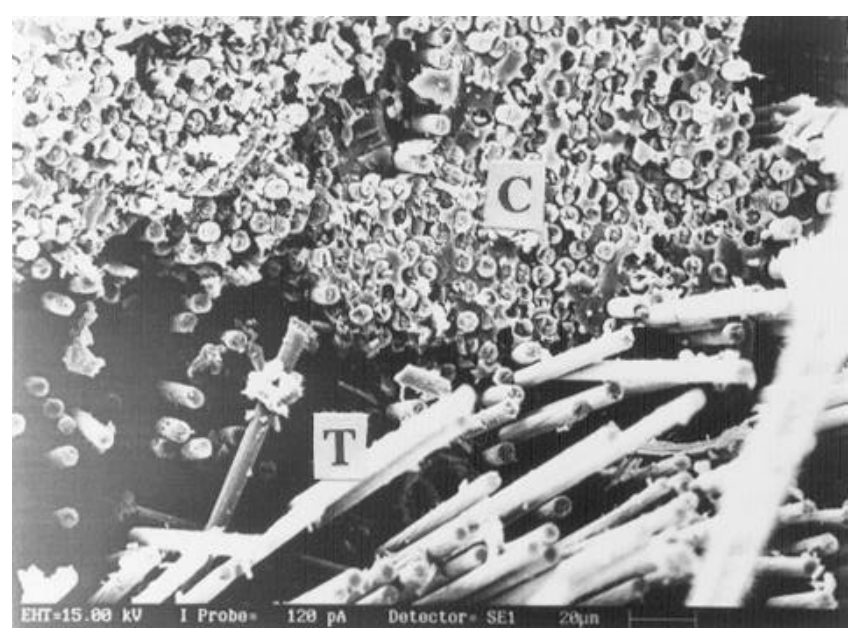

Figure 11. SEM photograph of VLMS-48 composite broken under single impact showing debonding as well as the fibre pull-out. 
matrix was observed for both types of composites examined indicating that the technique adopted to process the samples were satisfactory, eliminating much of the composite weaknesses contributed by the defects incorporated during processing. DHMS-48 composites under flexural test showed heavy debonding with fibre pull-out and fracture at the tensile zone and shear fibre bundle fracture at the compressive zone in conformity with the loaddisplacement curve shown in figure 4. Samples when broken under single impact for DHMS-48 at an impact energy level of $562.3 \mathrm{~N}$-mm (figure 10) showed a continuous debonding followed by a shear breakage of the fibre bundle. On the other hand, for VLMS-48 samples broken under single impact at an impact energy level of 394.6 N-mm, showed a debonding with shear breakage of the fibre bundle as well as the fibre pull-out (figure 11). In region II, at the energy level of $340.4 \mathrm{~N}-\mathrm{mm}$ and $197 \cdot 1 \mathrm{~N}-\mathrm{mm}$, the fracture surfaces of DHMS-48 and

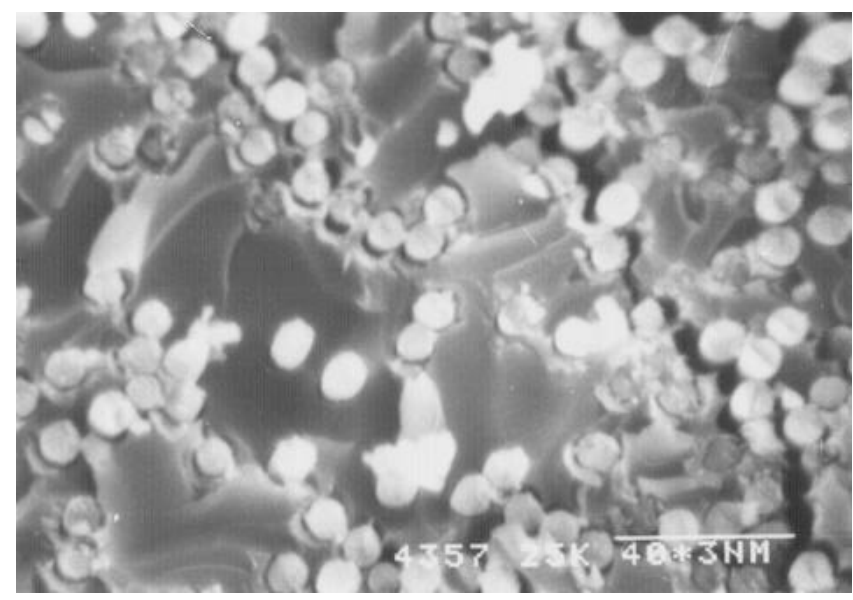

Figure 12. SEM photograph of DHMS-48 composite showing a propagating matrix along the interface $\left(E_{\text {appl }}=340.4 \mathrm{~N}-\mathrm{mm}\right.$, $N=502$ cycles).

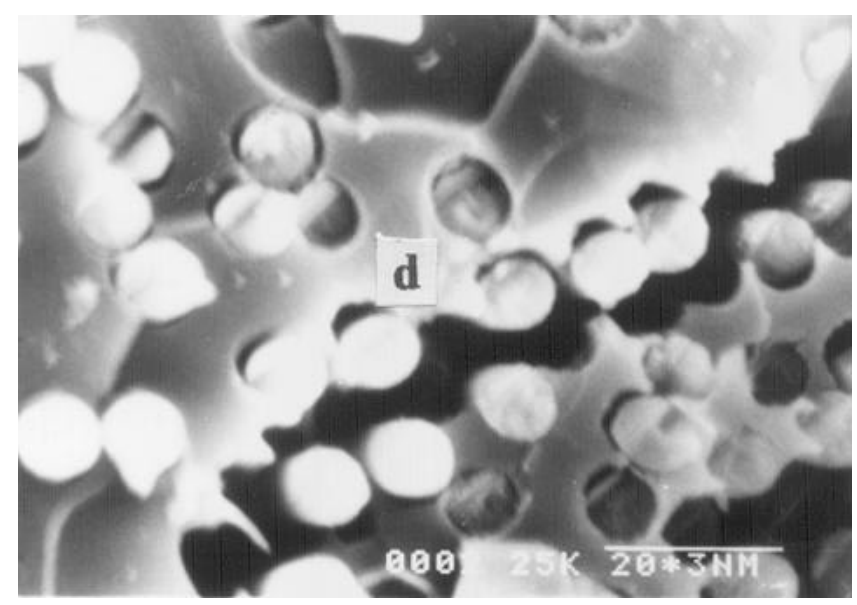

Figure 13. SEM photograph of VLMS-48 composite showing matrix cracking and debonding $\left(E_{\text {appl }}=197 \cdot 1 \mathrm{~N}-\mathrm{mm}, N=390\right.$ cycles, $d=$ debonding).
VLMS-48 samples respectively, showed debonding and matrix cracking (figures 12 and 13). In region III, under impact fatigue at $160 \cdot 4 \mathrm{~N}-\mathrm{mm}$ energy level the fracture surfaces of DHMS-48 showed (figure 14) matrix cracking with fibre pull-out. The VLMS-48 samples displayed similar fracture behaviour under fatigue conditions at the energy level of $60 \cdot 1 \mathrm{~N}-\mathrm{mm}$ (figure 15). In conformity with Gamstedt and Talreja (1999) the failures of the composites followed a set pattern of debonding and crack initiation of the matrix at the plateau region I propagating along the fibre-resin interface. As the samples endured more impacts, the damage in the form of debond and matrix cracking multiplied eventually affecting the fibres leading to fracture. The later is more predominant when the samples were fatigued for a large number of cycles beyond $10^{3}$ cycles. This is reflected in the measurements of the residual properties at $50 \%-\mathrm{N}$. The matrix cracking and debonding were more effective on the flexural

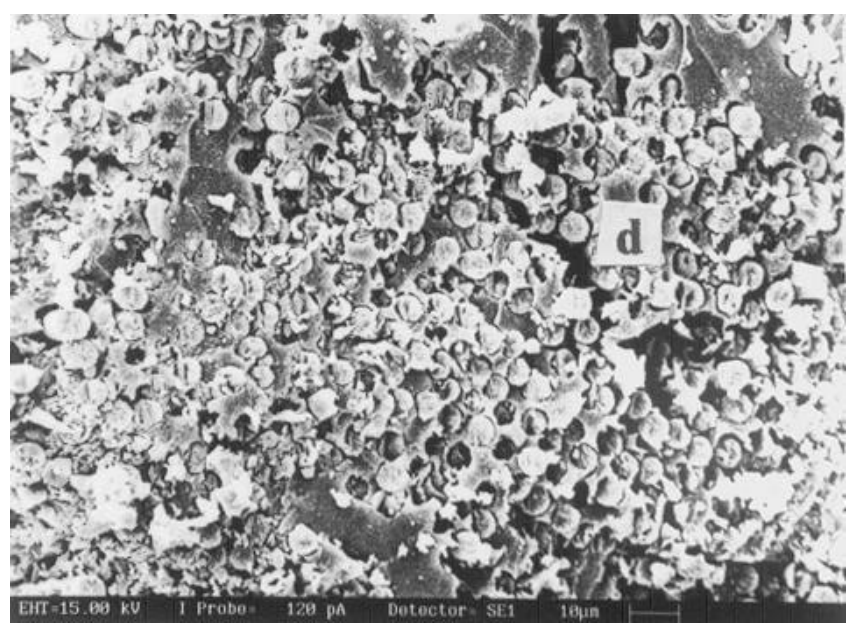

Figure 14. SEM photograph of DHMS-48 composite showing a combined failure having debond cracks, fibre fracture and pull-out ( $E_{\text {appl }}=160 \cdot 5 \mathrm{~N}-\mathrm{mm}, N=16500$ cycles, $d=$ debonding $)$.

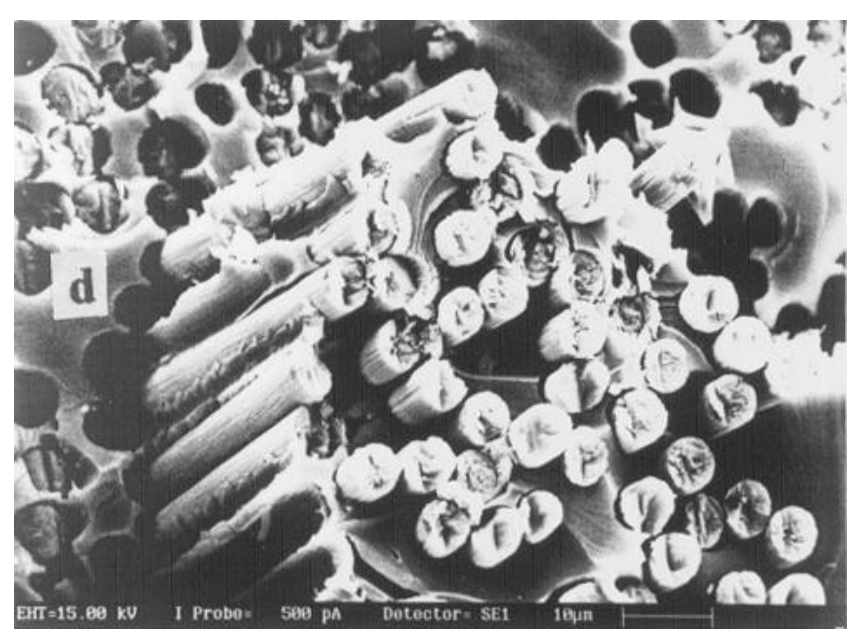

Figure 15. SEM photograph of VLMS-48 composite showing fibre fracture and pull-out $\left(E_{\text {appl }}=60 \cdot 1 \mathrm{~N}-\mathrm{mm}, N=6000\right.$ cycles $)$. 
strength property than the modulus and toughness. The later was being more dependent on the retained integrity of the fibres. At the endurance cycles beyond $5 \times 10^{3}$, the residual strength and toughness of DHMS-48 and VLMS48 were as high as $90 \%$ and $85 \%$ of their single impact values respectively. The damages caused at high impact energy levels but low impact cycles were not sufficient to cause serious drop in the residual properties. It was only when the impact cycles were large above $10^{3}$ cycles at lower impact energy levels that the multiplicity of the cracks and fibre damage caused the fall in residual properties.

\section{Conclusions}

The existence of an impact fatigue behaviour of an $\mathrm{S}-\mathrm{N}$ type for two types of carbon fibre reinforced vinylester composites has been demonstrated when tested beyond $10^{4}$ cycles. Both the composite samples showed an initial plateau region to $10^{2}$ impact cycles followed by a progressive endurance with decreasing applied impact energy below the threshold fracture energy having endurance limits at about $71 \%$ of the critical impact energy for DHMS-48 and $85 \%$ for VLMS-48 composite samples. The unbroken impact fatigued samples at about $50 \%$ of the endured number of cycles $(50 \%-\mathrm{N})$ at each subcritical impact loads showed progressive decrease in properties with increasing number of impact cycles. Microstructural studies of the fractured surfaces revealed debonding, with cracks originating in the matrix by the contact stresses. Flaws coalescing and propagating along the interface constitute the onset of fatigue damage. The debond cracks grew in size and the number leading to loss in strength and stiffness. Only when they grew to sufficient volume the composites failed. The composites having superior fibre properties showed superior fatigue properties. The retained integrity of the fibre properties being more effective in the overall fatigue behaviour of the composites examined.

\section{Acknowledgements}

The authors are grateful to Mrs M Sarkar, Indian Jute Industries Research Association (IJIRA), for her help in carrying out the tests in Instron. Thanks are also due to Mr S K Dalui, Central Glass and Ceramic Research Institute in carrying out the fibre testing. The Director General, Geological Survey of India (GSI), and Dr S Shome in particular are acknowledged for SEM facility. Directors of IJIRA, CGCRI and IACS are gratefully acknowledged for their kind permission to use their laboratory facilities. Financial assistance from the HRD, Council of Scientific and Industrial Research, New Delhi, is gratefully acknowledged.

\section{References}

Agarwal B D and Joneja S K 1979 Fibre Sci. \& Technol. 12 341

Bhateja S K, Rieke J K and Andrews E H 1979 J. Mater. Sci. 14 2103

Dauskardt R H, Ritchie R O and Cox B N 1993 Adv. Mater. Process. 726

Gamstedt E K and Talreja R 1999 J. Mater. Sci. 342535

Jang B P, Huang C T, Hsieh C Y, Kowbel W and Jang B Z 1991 J. Comp. Mater. 251171

Jang B P, Kowbel W and Jang B Z 1992 Comp. Sci. \& Technol. 44107

Lhymn C 1985a J. Mater. Sci. Lett. 41221

Lhymn C 1985b J. Mater. Sci. Lett. 41429

Maity S and Sarkar B K 1995 Bull. Mater. Sci. 18857

Maity S, Chaudhuri J and Sarkar B K 1994 Trans. Indian Ceram. Soc. $\mathbf{5 3} 1$

Ohishi F, Nakamura S, Koyama D, Minabe K, Fujisawa Y and Tsuruga Y 1976 J. Appl. Polym. Sci. 2079

Rotem A 1988 J. Comp. Technol. Res. 74

Sarkar B K and Glinn T G J 1971 J. Mater. Sci. 54601

Schater E, Engel P A and Bayer R G 1979 J. Appl. Polym. Sci. 241503

Studman C J and Field J E 1977 Wear 41373

Takemori M T 1982 J. Mater. Sci. 17164

Wyrick D A and Adams D F 1988 J. Comp. Mater. 22749 